\title{
Динамика активности экспрессии генов серотонинергической, глутаматергической системы и генов нейропластичного пути в разных моделях хронического стресса
}

\author{
(C) Е.В. Валеева ${ }^{1,2 *}$, О.А. Кравцова ${ }^{1}$ \\ ${ }^{1}$ Казанский фредеральный университет \\ Россия, 420008, Кремлевская, 18 \\ ${ }^{2}$ Казанский государственный медицинский университет \\ Россия, 420012, Бутлерова, 49 \\ *E-mail:vevaleeva@ya.ru
}

Одной из проблем хронического стресса является нарушение регуляции нейротрансмиттерных систем и атрофии нейронов в связи с потерей синаптических связей. В работе представлены результаты изменения относительного уровня экспрессии генов в крови некоторых нейротрансмиттерных систем и генов, участвующих в нейропластичности, на вивальной модели крыс линии Вистар при воздействии хронического стресса в условиях иммобилизации и изнурительной физической нагрузки. Показано изменение транскрипционной активности Slc6a4, Creb1 и Adra2c под влиянием хронического стресса в разный период воздействия.

Ключевые слова: хронический стресс, серотонинергическая система, глутаматергическая система, экспрессия генов.

Любой стресс является адаптивным ответом организма (аллостазом), контролируемым несколькими системами, в основном вегетативной нервной системой и гипоталамогипофризарно-надпочечниковой системой [1-3]. Однако при сверхнагрузке данных систем возникают ряд проблем у организма.

Хронический стресс - это длительное воздействие экстремальных факторов (стрессоров) на организм, вызывающий дисгомеостаз. Хронический стресс приводит к характерным нарушениям со стороны нервной и эндокринной системы, вызывая такие патологии как депрессия, истощение, и ускоряет дегенеративное старение [4].

Нейротрансмиттерные системы играют ключевую роль в регуляции ответа организма при стрессе. Серотонин вовлечен в патогенез развития различных психических расстройств таких, как депрессия, тревожные расстройства, шизофрения. Так, у пациентов с паническими расстройствами уровень серотонина 4-х кратно увеличен по сравнению со здоровой выборкой [5]. При стрессе также наблюдается изменение активности передачи и высвобождение другого нейротрансмиттера - глутамата в зависимости от активации кортикостерона [6]. У людей, страдающих депрессией, показано, что уровень глутамата также был повышен [7]. Помимо нарушений, происходящих в серотониергичексой и глутаматергической системе, наблюдаются изменения во внутриклеточной передаче сигналов, нейротрофических механизмов, нейрогенезе и синаптической пластичности [8]. Показано, что ответ на стресс будет зависеть от индивидуальных генетических различий, стрессоустойчивости, от типа и степени стресса, а также продолжительности воздействия. 
В связи с этим целью данной работы являлось оценить влияние хронического стресса в условиях иммобилизации и изнурительных фризических нагрузок на изменение экспрессии относительного уровня генов серотонинергической (Slc6a4, Htr4), гена глутаматергической системы (Adra2c) и генов, участвующих в нейропластичности (Creb1, Bdnf) в крови у крыс линии Вистар.

Материалы и методы. Исследование было проведено на 88 крысах Wistar (34 самок, 54 самцов) возрастом 90 дней. Эксперименты были одобрены Локальным этическим комитетом К(П)ФУ (протокол №20 от 27 декабря 2019 г.).

Моделирование хронического стресса проводили в условиях иммобилизации, изнурительной фризической нагрузки и их комбинированного воздействия. В связи с этим были сфрормированы 4 группы крыс: I - контрольная (n=21); II - крысы, подвергавшиеся фризической нагрузке в тесте «Вынужденное плавание с грузом» $(\Phi \mathrm{H}, \mathrm{n}=22)$; III - животные, подвергавшиеся хроническому иммобилизационному стрессу (ИС, n=19); IV группа - животные, которые подвергались комплексной комбинации тестов из II и III группы $(\Phi H+И C, n=26)$.

Проведение теста «Вынужденное плавание с грузом» проходило 7 минут в специальном водном бассейне (НПК «Открытая наука», Красногорск) 2 раза в неделю в течение 270 сут. Груз, подвязываемый вокруг брюшины шнурком, весил 8\% от веса тела [9]. Хронический иммобилизационный стресс у крыс вызывался ежедневной 90-минутной иммобилизацией на протяжении 14 суток каждые 90 дней в специальном пеналефриксаторе (НПК «Открытая наука», Красногорск) [10]. Опытную IV группу крыс подвергали комбинированному воздействию стрессоров II и III группы.

Забор крови из хвостовой вены крыс производили в начальной точке (0 сут) до воздействия стрессом, после 90-а, 180-и и 270-и сут исследования. Выделение суммарной PHК осуществляли реагентом ExtractRNA (Евроген, Москва) с последующим синтезом кДНК с помощью набора MMLV RT kit (Евроген, Москва). Анализ относительного уровня экспрессии генов Slc6a4, Htr4, Adra2c, Creb1, Bdnf был проведён количественной ПЦР в реальном времени с использованием собственно сконструированных праймеров [11] и мастер микса с интеркалирующим красителем Sybr Green [Евроген, Москва]. Peфреренсным геном являлся Gapdh. Расчет относительного уровня экспрессии генов был проведен с помощью метода $2^{-\Delta \Delta \mathrm{Ct}}[12]$.

Результаты. В ходе анализа относительного уровня экспрессии гена Slc6a4, кодирующего транспортер серотонина, было обнаружено, что экспрессия SIc6a4 на 90 сут повышалась в 2 раза у крыс, подвергавшиеся комбинированному воздействию стрессовых фракторов $(\Phi \mathrm{H}+И С)(p=0,04)$. На 180 сут эксперимента уровень экспрессии гена Slc6a4 значимо повышался во всех опытных и контрольной группе: у контроля повышался в 6 раз $(p=0,0002)$, в группе $\Phi$ в 29 раз $(p=0,003)$, в группе ИС в 98 раз $\left(p=3,4^{*} 10^{-18}\right)$ и в группе $Ф \mathrm{H}+И С$ в 49 раз $\left(p=6,7^{*} 10^{-11}\right)$. При дальнейшем анализе уровня экспрессии S/c6a4 на 180-е сут исследования между группами наблюдалось статистически значимое различие: уровень экспрессии Slc6a4 у крыс в условиях иммобилизационного стресса были выше значений контроля $\left(p=3,1^{*} 10^{-8}\right), \Phi Н(p=0,04)$ и $Ф Н+И С$ $(p=0,001)$ (Рисунок 1).

При анализе относительного уровня экспрессии гена Htr4, который кодирует рецептор серотонина, значимых изменений в динамике и между испытуемыми группами в каждом периоде не было обнаружено у испытуемых групп $(p>0,05)$.

Сравнительный анализ опытных групп с начальной точкой показал, что на 180-е сут относительный уровень экспрессии Adra2c гена, кодирующего альфа адренорецептор 2C, в группе ИС было повышено в 2 раза $(p=0,03)$ (Рисунок 1). Между опытными груп- 
пами значимой разницы уровня экспрессии гена Adra2c в крови не было обнаружено в каждом периоде наблюдений ( $p>0,05)$.

При сравнительной оценке значения относительного уровня гена Bdnf (нейротрофического фрактора мозга) не было обнаружено значимых изменений в исследуемые периоды и воздействия изучаемых стрессоров ( $>>0,05)$. На 90-е сут у крыс, подвергавшиеся воздействию ИС, уровень экспрессии гена Bdnf был ниже контрольной $(p=0,02)$. На 180-е сут исследования, наоборот, в группе ИС уровень экспрессии гена значимо повышался контрольной группы и группы ФН этого же периода ( $p=0,001$ и $p=0,002$, соответственно) (Рисунок 1).

Анализ транскрипционной активности гена Creb1 на 180 сут снижался значимо во всех опытных группах $(p<0,05)$. На 180-е сут уровень экспрессии Creb1 был значимо ниже в группе крыс, подвергавшиеся ИС, по сравнению с контролем ( $p=0,0004)$ и группой, подвергавшиеся $Ф \mathrm{H}(\mathrm{p}=0,02)$. Так же в данном периоде наблюдалось снижение экспрессии Creb1 в группе ФН+ИС по сравнению с контролем $(p=0,02)$. На 270-е сут эксперимента уровень экспрессии гена Creb1 был ниже в крови у крыс в группе $Ф \mathrm{H}+И C$ по сравнению с крысами из контрольной группы $(p=0,04)$ (Рисунок 1).

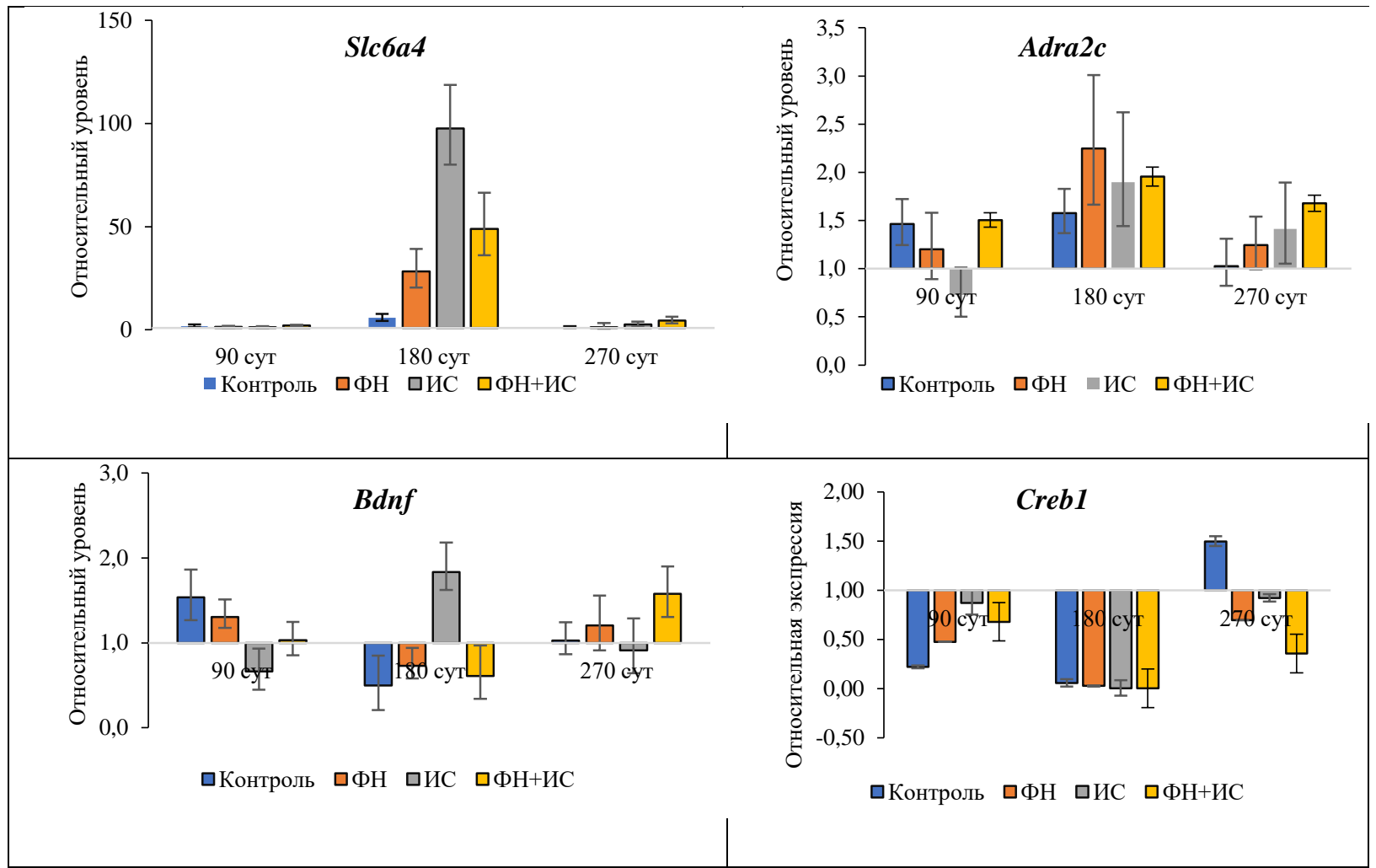

Рисунок 1. Динамика относительного уровня экспрессии генов Slc6a4, Adra2c, Bdnf и Creb1 в крови различных моделей хронического стресса.

Примечание: ФН - физическая нагрузка, ИС - иммобилизационный стресс.

Выводы. Таким образом, в ходе анализа изменения относительного уровня генов серотонинергической, глутаматергической и генов, участвующих в нейропластичности, было обнаружено, что транскрипционная активность Slc6a4, Creb1 u Adra2c изменяется под влиянием хронического стресса в разный период воздействия. Профиль экспрессии генов Slc6a4 и Creb1 обладают высокой степенью чувствительности к воздействию хронического стресса в условиях иммобилизации, изнурительной фризической нагрузки и их комбинированного воздействия на 180 сут, а в условиях иммобилизаци- 
онного стресса на 180 сут подходящим маркером хронического стресса может служить повышенный уровень экспрессии Adra2c.

Работа поддержана грантом РФФИ 19-34-90171.

\section{Литература}

1. Harvey S., Phillips J. G., Rees A., Hall T. R. Stress and adrenal function //Journal of Experimental Zoology. 1984. V. 232. № 3. P. 633-645.

2. Collip J.B. Inhibitory hormones and the principle of inverse response //Annals of Internal Medicine.1934. V. 8. № 1. P. 10-13.

3. Sterling P., Eyer J. Allostasis: A new paradigm to explain arousal pathology// Life Stress, Cognition and Health. // John Wiley \& Sons. 1988. P. 629-649.

4. McEwen B.S. Redefining neuroendocrinology: epigenetics of brain-body communication over the life course // Front. Neuroendocrinol. 2017. V. 49. P. 8-30.

5. Esler M., Lambert E., Alvarenga M., Socratous F., Richards J., Esler M., Lambert E., Alvarenga M., Socratous F., Richards J., Barton D., Pier C., Brenchley C., Dawood T., Hastings J., Guo L., Haikerwal D., Kaye D., Jennings G, Kalff V., Kelly M., Wiesner G., Lambert $\mathrm{G}$. Increased brain serotonin turnover in panic disorder patients in the absence of a panic attack: reduction by a selective serotonin reuptake inhibitor //Stress. 2007. V. 10. № 3. P. 295-304.

6. Gorman J.M., Docherty J.P. A hypothesized role for dendritic remodeling in the etiology of mood and anxiety disorders // J. Neuropsychiatry Clin. Neurosci. 2010. V.22. P. 256-264.

7. Duman R.S. Pathophysiology of depression and innovative treatments: remodeling glutamatergic synaptic connections// Dialogues Clin. Neurosci. 2014. V. 16. № 1. P. 11-27.

8. Musazzi L., Treccani G., Mallei A., Popoli M. The action of antidepressants on the glutamate system: regulation of glutamate release and glutamate receptors // Biol Psychiatry. 2013. V. 73. P.1180-1188.

9. Beaton J.R., Feleki V. Effect of diet and water temperature on exhaustion time of swimming rats // Canadian journal of physiology and pharmacology. 1967. V. 45. № 2. P. 360363.

10. Bhatia N., Jaggi A.S., Singh N., Anand P., Dhawan R.Adaptogenic potential of curcumin in experimental chronic stress and chronic unpredictable stress-induced memory deficits and alterations in functional homeostasis // Journal of natural medicines. 2011. V. 65. P. 532-543.

11. BLAST (2021): [сайт]. URL: https://blast.ncbi.nlm.nih.gov

12. Livak K.J., Schmittgen T.D. Analysis of relative gene expression data using real-time quantitative PCR and the $2^{-\Delta \Delta \mathrm{Ct}}$ method // Methods. 2001. V. 25. № 4. P. 402-408. 
Dynamics of the expression activity of genes of the serotonergic, glutamatergic systems and genes of the neuroplastic pathway in different models of chronic stress

E.V. Valeeva ${ }^{1,2^{*}}$, O.A. Kravcova ${ }^{1}$

${ }^{1}$ Kazan Federal University, Russia, 420008, Kremlevskaya str., 18

${ }^{2}$ Kazan State Medical University, Russia, 420012, Butlerova str., 49

*E-mail: vevaleeva@ya.ru

One of the problems of chronic stress is the dysregulation of neurotransmitter systems and neuronal atrophy due to the loss of synaptic connections. The study presents the results of changes in the relative level of gene expression of some neurotransmitter systems and genes involved in neuroplasticity in a vival model of Wistar rats under the influence of chronic stress under conditions of immobilization and exhausting physical activity. It was shown that the transcriptional activity of SIc6a4, Creb1 and Adra2c changes under the influence of chronic stress in different periods of exposure.

Key words: chronic stress, serotonergic system, glutamatergic system, gene expression. 